\title{
The Construction and Implementation of New Staff Training Classes Benchmarking System -- Taking the Practice of SGTC New Staff Training Classes Benchmarking as an Example
}

\author{
Jiang Yang ${ }^{1, a}$ and Li Xiuhua ${ }^{2, b}$ \\ ${ }^{1}$ Jinan Campus, State Grid of China Technology College, JInan, Shandong, China \\ ${ }^{2}$ Jinan Campus, State Grid of China Technology College, JInan, Shandong, China \\ a109029743@qq.com, bfallingsnow201007@163.com \\ Jiang Yang
}

\begin{abstract}
Keywords: New staff training classes, Classes benchmarking system, Realistic background, Implementation effect.
\end{abstract}

\begin{abstract}
In order to enhance the level of new staff training classes management, Trainee and student management Division of Jinan Campus Committee of State Grid of China Technology College, responding to the college's appeal to omnidirectional benchmarking, gradually establishes a sound system for classes benchmarking and implement the benchmarking management among all the new staff training classes. The implementation of classes benchmarking helps to create the positively competitive atmosphere of continuous improvement and transcendence among new staff classes, stimulate the trainees to raise their comprehensive abilities as well as their professional techniques, and improve the overall quality of the new staff training. This paper expounds the realistic background of the new staff training classes benchmarking, the specific measures to construct the benchmarking system, and the implementation effects of the benchmarking management, with the aim of providing reference on how to enhance trainees management in the process of large-scale centralized training.
\end{abstract}

\section{新员工培训班级对标管理体系的构建和实施一一国网技术学院新员 工班级对标管理实践为例}

\author{
姜杨 ${ }^{1, a}$, 李秀华 $2, \mathrm{~b}$ \\ 1 国网技术学院济南校区, 济南, 山东, 中国 \\ 2国网技术学院济南校区, 济南, 山东, 中国 \\ a109029743@qq.com, bfallingsnow201007@163.com \\ 姜杨
}

关键词：新员工培训班级，班级对标管理体系，现实背景，实施效果

中文摘要. 为了提升新员工班级管理水平，国网技术学院济南校区学员学生管理处贯彻学院 开展对标管理全覆盖的要求, 逐步建立系统完整的班级对标管理体系, 并面向全体新员工学 员班级开展班级对标管理，营造了班级之间对比改进、不断超越的良性竞争氛围，有效激励 学员不断提升自己的综合素质和职业素养，进而从整体上提升了新员工培训的质量。本文阐 述了新员工班级对标管理的现实背景、对标体系构建的具体措施以及对标管理的实施效果， 旨在为在大规模集中培训中如何加强学员管理提供参考。 


\section{1. 引言}

近年来，国家电网公司（以下简称公司）坚持以人为本,实施人才强企战略，增加教育培 训投入, 大力开展全员覆盖的新入职员工集中培训。每年在国网技术学院参加国网新员工集 中培训的总人数多达 10000 人以上, 总班数多达 200 个班左右, 培训周期 $1-3$ 个月不等。大规模 集中培训给学员管理工作带来了挑战, 而学院全面建设一流企业大学的发展目标又向学员管 理工作提出了更高的要求。学院2017年工作报告中提出, 要强化 “三基” 管理, 推进工作落 实, 建立学员学生班级对标管理制度。济南校区学管处认真贯彻学院开展班级对标管理的要 求, 全方位、多维度、深层次构建班级对标体系, 并面向济南校区全体新员工学员班级深入 开展班级对标管理。

对标管理起源于 20 世纪70年代的美国。最初, 人们把对标作为一种调差比较的基准方法, 利用对标查找与其它公司的差距。对标就是对照标杆, 寻找差距, 不断探索达到或超越标杆 水平的方法与途径。对标管理可定义为 “企业通过在经营管理的各个层次、业务单元及环节 寻求达到卓越绩效的最佳实践, 分析与最佳实践的差距及其原因, 采取针对性措施实现根本 改善和创新超越的持续实践过程”, 目的是 “了解最佳实践、明确潜力目标、激励内部组织、 制定实施行动计划促进业绩显著提升 1 ” [1]。对标管理方法蕴含了现代知识管理中追求竞争 优势的本质特性。学员班级是学员管理的基本单位, 班级对标管理是一个促进班级时刻保持 “竞技状态”、瞄准标杆、对比改进, 不断超越的过程。通过新员工培训班级对标管理体系 的构建和实施, 使对标理念和对标要求真正融入班级管理, 全面提升新员工培训班级管理水 平, 从而从整体上提高培训质量, 对于组织类似于国网公司新员工培训的大规模集中培训、 强化学员管理具有实际的推广价值和借鉴意义。

\section{2. 开展班级对标管理的现实背景}

\section{1 班级对标管理是助力学院强化 “三基” 管理的重要举措}

国家电网公司要求: “面对艰巨的发展任务, 在发展上要强化 “三基” 管理, 坚持重心 下沉, 尤其是进一步强化基层组织机构的管理。” [2]学院在工作中及时准确把握公司的思 路和要求, 在学院重点工作中强化基层建设、基础管理和基本功锻炼, 为进一步提升学院综合 管理水平注入了强劲动力。对学院来说, 班级是组织员工完成培训管理任务的最基本单位, 班级建设是学院作为公司企业大学落实公司要求、服务公司发展的基础。为助力学院三基管 理建设, 济南校区学管处高度重视班级对标管理体系建设, 强化组织领导, 创新管理思路, 以抓基层、基础、基本功为重点, 加强班级对标管理, 旨在提高基层建设整体水平, 保障学 院培训工作安定、有序、顺利进行。

\section{2 班级对标管理是深化学院开展校区对标的具体落实}

为全面提升各校区管理服务水平，学院决定在三个校区间开展同业对标，建立基于 “安 全管理指标+学员学生管理指标+后勤管理指标+员工队伍建设指标” 的同业对标指标体系。 其中学员学生管理指标重点从学员学生活动和学员学生环境两个方面开展评价, 主要包括“上 课出勤率、早操出勤率、教室和公寓标准化管理执行率、违规违纪人次等指标。济南校区学 管处响应学院关于开展校区对标的要求, 积极构建和实施校区内班级对标管理。在校区对标 方案中学员管理指标的基础上, 班级对标体系增加设置 “安全管理、卫生检查和综合纪律检 查” 等指标, 进一步规范学员学生早操、课堂行为表现, 督促学员学生保持干净整洁的学习、 住宿环境, 展现公司员工良好的精神面貌。班级对标体系不仅体现了校区对标的精髓, 而且 还对院区对标内容进行了深化和拓展, 确保校区对标的深入实践和具体落实, 从而切实促进 学员管理水平的提升, 更好地服务于学院建设国际一流大学的发展策略。 


\section{3 班级对标管理是激励学员践行公司企业文化的有效途径}

公司企业文化传播是新入职员工培训的重要内容，新员工班级对标管理将国网公司企业 文化理念渗透到管理的全过程、全方位、各环节, 有效促进企业文化传播和落地。班级对标 体系覆盖党团工作、学习管理、体育活动、文艺活动、生活服务、宣传报道、综合纪律管理 等指标, 将班级对标内容与企业文化宣贯紧密结合, 强化对公司企业文化的宣贯, 引导学员 树立正确的世界观、人生观、价值观, 增强学员的自律意识和竞争意识, 激励他们深刻理解 企业文化的基础上积极践行 “诚信、责任、创新、奉献” 的核心价值观。

\section{3. 构建班级对标管理体系的具体措施}

班级对标是在认真调研新员工培训班级管理需求的基础上建立的对标管理体系，包括调 研班级管理需求、制定对标指标体系, 组建对标实施机构, 制定对标工作制度, 健全对标考 核机制, 建立对标改进机制等六个环节, 实现新员工培训班级的闭环管理。班级对标内容覆 盖学员管理的各个方面和环节, 主要包括安全管理、卫生检查、党团工作、学习管理、体育 活动、文艺活动、生活服务、宣传报道、综合纪律检查等九个维度。

\section{1 调研新员工培训班级管理需求}

国网公司新员工集中培训班学员是班级对标工作调研的主要对象。在需求调研阶段, 通 过举办由学管会和班委会学员干部、班级学员代表参加的座谈会, 现场检查学员早操、晚自 习、卫生、综合纪律现状, 关注班级微信群等, 汇总了以下普遍存在的班级管理问题: 班级 自我管理能力较弱、个别学员安全意识淡薄、作风涣散, 少数学员守纪观念不强, 学管会与 班委之间缺乏有效的沟通等。通过认真分析以上问题的成因, 结合学院大规模集中培训的特 点, 逐步明确新员工班级的管理需求为: 以培养合格国网员工为目标, 以安全稳定为中心, 以制度建设为保障, 以 “安全管理、纪律检查和活动开展” 为主线, 严格管理、精准量化、 全员激励、持续改进。

\section{2 设置班级对标指标体系}

“对标管理要从科学管理、量化管理以及落实 “严、准、细、精” 的 管理要求的角度出 发,科学设置指标体系,合理选择对标项目。”[3]在明确学员班级管理需求基础上, 围绕学院 的发展需求, 结合校区对标方案中的学员管理指标, 设置班级对标指标体系。指标设置中注 重指标的引导性、可比性、客观性和一致性。首先, 坚持问题导向, 指标设置覆盖学员管理 的重点、难点和共性问题; 如: 事假、迟到、早退等等。其次, 突出指标的可比性和客观性, 按照最大限度可量化原则选择可量化的指标, 如: 早操、上课、晚自习出勤率; 确保指标客 观准确、可比可控可操作。再次, 增加核心指标 (如违规用电、晚归等) 的分值比重, 突出 学管工作的重点流程和校区对标的关键环节, 实现对标体系内各项指标目标一致、权重均衡。 按照以上原则, 共梳理出九项对标维度, 19项一级指标和 40 项二级指标, 进一步确定各指 标的归口管理部门和人员、具体检查内容、分值和检查周期, 设置了导向一致、层层细化、 内容明确、计分清晰的班级对标指标体系。

\section{3 组建班级对标组织机构}

为了从组织管理上统一思想，充分发挥学员自我管理、自我监督的作用，明确了各部分 的岗位职责、分工协作和考核标准, 成立了学管处、学管会、班委会三位一体的组织机构:

（1）学管处是学员班级对标管理的牵头实施部门, 负责班级对标工作方案制定、对标工作开 展情况的监督、检查和指导; 负责汇总、审核班级对标检查分析报告; 负责对标结果的发布 和对标工作成效的总结评估。（2）学管会是班级对标工作的具体实施部门, 负责制定班级对 标细则, 与辅导员一起组织开展班级对标检查, 汇总对标成绩, 撰写对标检查分析报告。 
班委会负责班级对标工作的落实, 负责向班级全体学员宣贯班级对标制度, 动员全体学员积 极参与班级对标; 负责分析本班对标成绩, 找准差距与改进措施, 不断促进班级建设。在班 级对标工作中, 三者目标一致、各司其职、高效协作, 相互督促, 在对标实践中共同提升管 理技能, 为对标工作的顺利开展奠定组织基础。国网公司新员工集中培训班学员是班级对标 工作调研的主要对象。在需求调研阶段, 通过举办由学管会和班委会学员干部、班级学员代 表参加的座谈会, 现场检查学员早操、晚自习、卫生、综合纪律现状, 关注班级微信群等, 汇总了以下普遍存在的班级管理问题: 班级自我管理能力较弱、个别学员安全意识淡薄、作 风涣散, 少数学员守纪观念不强, 学管会与班委之间缺乏有效的沟通等。通过认真分析以上 问题的成因, 结合学院大规模集中培训的特点, 逐步明确新员工班级的管理需求为: 以培养 合格国网员工为目标, 以安全稳定为中心, 以制度建设为保障, 以 “安全管理、纪律检查和 活动开展” 为主线, 严格管理、精准量化、全员激励、持续改进。

\section{4 制定班级对标工作制度}

为规范班级对标工作的开展, 在广泛征求意见的基础上, 制定班级对标工作制度, 并在 执行过程中不断补充、完善。对标工作制度主要包括济南校区班级对标工作细则和安全管理、 卫生检查、党团工作、学习管理、体育活动、文艺活动、生活服务、宣传报道、综合纪律检 查九个维度的对标工作细则, 规定了对标工作的总体方案、指标体系以及各维度对标工作宗 旨、工作职责和工作程序 (包括组织机构、对标标准、对标方式和考核细则) , 覆盖班级对 标工作的各个方面和各个环节。

对标工作制度规定了对标工作原则、标准, 在明确工作职责和分工的基础上要求各级工 作人员服务大局、公正管理，保证了对标工作的严谨性和公正性。同时，对标工作制度明确 了对标内容、对标方法、时间节点和考核细则, 规定每天开展对标检查并公示结果、每周汇 总对标检查发现的问题并通报、每月汇总班级对标成绩并落实考核，形成 “日检查、周通报、 月考核” 的常态化对标工作流程, 使对标工作融入到学员的日常管理工作中, 确保对标管理 的标准化、规范化、程序化。

\section{5 健全班级对标考核机制}

为确保对标管理取得实效，在总结学员管理考核经验的基础上，制定了班级对标管理考 核办法, 进一步建立健全班级对标考核机制。采取班级对标成绩与学员考核成绩挂钩的方法, 将班级对标工作纳入到学员考核体系中。一方面, 将学员个人量化加减分按比例记入到班级 对标成绩。通过将学员个人表现量化到班级对标的考核方法, 有效激励学员自觉遵守纪律、 积极参加企业文化践行活动。另一方面, 进一步细化班级对标指标考核条目, 将班级对标的 各项指标成绩准确、及时量化到每一位学员的日常表现、班级工作和企业文化践行成绩中, 并将班级排名与班级、学员先优评比挂钩, 使班级对标排名成为先进班级评比、学员先优评 比的重要依据。

通过全员全过程双向对标考核，不仅可以将学院的管理要求以明确可量化的指标及时、 准确地传达给每一位学员, 有效督促学员规范日常行为、培养良好的职业素养; 而且可以有 效激励全体学员增强集体荣誉感, 提升班级的凝聚力, 促进良好班风的形成, 从而提升新员 工班级的整体管理水平。

\section{6 完善班级对标改进机制}

对标管理不是短期行为, 而是 “一个持续改进的动态管理过程” [4]为了不断提升班级对 标管理水平, 应及时评估班级对标管理的结果, 总结对标管理经验, 持续改进班级对标管理 体系。

班委、学管会各个实施落实部门及时总结对标开展情况, 学管处定期撰写对标工作报告, 分析班级对标管理的成效和不足。通过整理对标管理最佳案例, 沉淀了先进的对标经验, 并 
将经验固化、补充进指标体系和工作标准。同时查找差距、查摆问题，针对突出问题进行调 研，通过问卷调查、座谈搜集资料，分析问题成因及影响因素，并结合班级管理的现状和发 展要求, 制定对标工作改进计划, 明确努力方向及改进措施, 不断完善班级对标管理, 形成 对标、总结、提升工作闭环。

\section{4. 班级对标管理的实施效果}

自班级对标工作实施以来, 通过强化管理、精准考核和双重激励形成班级 “你追我赶” 的良性竞争氛围, 开创了全员参与对标、全员努力创优的良好局面, 班级对标管理成效显著。

\section{1 校区安全隐患减少}

通过安全检查和综合纪律检查对标，学员宿舍发现使用违禁电器、校园流动抽烟等危险 行为大幅减少, 晚归、饮酒等重大违纪行为基本杜绝。班级对标最大程度上减少了校园安全 隐患，为保障培训顺利进行打下坚实的基础。

\section{2 班级风貌积极向上}

通过早操、上课、晚自习对标，学员早操、上课、晚自习出勤情况大为好转, 出勤率保 持 $98 \%$ 以上, 基本杜绝旷课、旷操、旷晚自习现象。实施卫生对标管理后, 教室卫生达标率 达到 $99 \%$ 以上, 宿舍内务达标率由原来的 $80 \%$ 左右提高到 $95 \%$ 左右。班级对标管理实施后, 班 风班貌焕然一新, 早操队伍整齐, 课堂秩序井然, 教室、宿舍清洁、美观, 展现了学员积极 向上的精神面貌。

\section{3 学员综合能力不断提高}

在党建工作、文体活动、宣传报道等对标工作中，围绕企业文化建设，积极开展形式多 样、内容精彩的党团活动、文体活动, 强化了对学员的思想引领和理想信念教育, 全面提升 了学员的党性修养和思想政治觉悟, 不断激励学员在展示自我、提升自我的过程中弘扬公司 企业文化、积极践行社会主义核心价值观, 同时提高了学员组织领导、沟通协调、宣传报道 等综合能力。

\section{4 学院培训质量全面提升}

班级对标管理,保障了校区内培训生活各个方面安定、有序进行，提升专业技能培训的实 效。同时, 在班级对标过程中, 全体学员充分领会班级对标的目的和要求, 在日常培训、生 活中自觉规范自己的行为, 不断提升自己的综合素质和职业素养, 为成长为优秀企业员工打 下坚实的基础。班级对标管理体系的建立和应用，不仅保证提升专业技能培训的实效，更促 进新员工培训发挥传递企业价值观、塑造德才兼备的优秀企业员工作用, 从而进一步从整体 上提高了新员工培训的质量和成效。

\section{5. 结束语}

综上所述，本文阐述了新员工班级对标管理的现实背景、对标体系构建的具体措施以及 对标管理的实施效果, 结合国网技术学院新员工班级对标管理的实践摸索出了增强学员管理 的一种路径, 对于大规模集中培训中如何增强学员管理具有较强的参考价值和借鉴意义。班 级对标管理是一项通过班级间良性竞争提升新员工硬软技能培养效果的系统工程, 同时又是 一个与时俱进、不断创新的动态过程。在以后的学员管理工作实践中, 我们将进一步围绕学 院的发展目标和新员工培训班级管理的需求, 不断审视班级对标管理体系的适用性和匹配性, 进一步规范工作制度, 健全考核机制, 及时对对标工作措施进行更新和改进, 精益求精, 持 之以恒, 在深入开展对标管理中不断提升学员管理水平, 为学院的全面发展做出更大的贡献。 


\section{Reference}

[1] The state capital development committee. The central enterprise strengthens the development of the world-class enterprise with international competitiveness. Benchmarking Guidance.[Z]. 2013. 18. 2.

[2] Y. Gao and B. Gu..Strengthening the three-base management and promoting the construction of teams. State Grid. 2015. 09.

[3] Corporate management department. Standard management standards (the latest edition). 2012.06.

[4] J.B.Li. How does the enterprise implement the benchmarking management?. Technological Development of Enterprise. 2012.08. 